\title{
Expression of the $h M L H 1$ gene is a possible predictor for the clinical response to 5-fluorouracil after a surgical resection in colorectal cancer
}

\author{
TAKAO IDE, YOSHIHIKO KITAJIMA, KAZUMA OHTAKA, \\ MAYUMI MITSUNO, YUJI NAKAFUSA and KOHJI MIYAZAKI \\ Department of Surgery, Saga University Faculty of Medicine, Saga, Japan
}

Received November 20, 2007; Accepted February 13, 2008

\begin{abstract}
The loss of a DNA mismatch repair occurs in $\sim 15 \%$ of sporadic colorectal cancer (CRC) and is usually caused by the lack of expression of the $h M L H 1$ gene due to promoter methylation. Despite undergoing adjuvant 5-fluorouracil (5-FU) therapy after a curative surgical resection, some patients with advanced-stage CRC develop recurrence. In the present study, we investigated whether the hMLH1 mRNA expression or promoter methylation is a prognostic factor in CRC patients treated with adjuvant 5-FU. The hMLH1 mRNA expression levels were measured by quantitative reverse transcription PCR in cancer and normal epithelial cells that were obtained from 94 CRC patients using a laser capture microdissection. Then, the methylation status of the hMLH1 promoter in the CRC tissues was examined by methylationspecific PCR. The hMLH1 mRNA expression levels were significantly lower in the cancer cells than in the normal mucosa $(\mathrm{p}<0.01)$ and the $h M L H 1$ mRNA expression levels in the cancer cells were significantly lower in the CRC tissues with methylated versus unmethylated $h M L H 1(\mathrm{p}<0.01)$ in the 94 patients. Among the 35 patients receiving adjuvant 5-FU, the disease-free survival rate was significantly better in the patients demonstrating a low $h M L H 1$ mRNA expression in the cancer cells in comparison to that of the patients with a high hMLH1 mRNA expression $(\mathrm{p}<0.01)$. Moreover, a multivariate analysis revealed that $h M L H 1$ mRNA expression was a significant independent prognostic factor for tumor recurrence
\end{abstract}

Correspondence to: Dr Kohji Miyazaki, Department of Surgery, Saga University Faculty of Medicine, 5-1-1 Nabeshima, Saga 849-8501, Japan

E-mail: miyazak2@cc.saga-u.ac.jp

Abbreviations: CRC, colorectal cancer; 5-FU, 5-fluorouracil; MSI, microsatellite instability; MMR, mismatch repair; LCM, laser capture microdissection; UICC, International Union Against Cancer; TS, thymidylate synthase; DPD, dihydropyrimidine dehydrogenase; OPRT, orotate phosphoribosyl transferase

Key words: hMLH1, 5-fluorouracil, colorectal cancer, adjuvant chemotherapy in CRC patients treated with adjuvant 5-FU. However, hMLH1 methylation was not correlated with the survival in these 35 patients. These data suggest that the $h M L H 1$ mRNA quantitation in colorectal cancer cells may be helpful for evaluating the prognosis of CRC patients receiving 5-FU-based adjuvant chemotherapy after a surgical resection.

\section{Introduction}

Colorectal cancer (CRC) is one of the most common malignancies worldwide. Despite major advances in the diagnosis and treatment of $\mathrm{CRC}$, the mortality has changed very little over the last three decades (1). Some patients develop a local or distant tumor recurrence even if a curative resection of the primary tumor is performed. The recurrence rate is significantly reduced using adjuvant treatment with 5 -fluorouracil (5-FU), nevertheless, $<30 \%$ of patients receiving adjuvant treatment still develop tumor recurrence within 5 years $(2,3)$.

There are at least two recognized pathways of colorectal carcinogenesis. The most common pathway, microsatellite stable (MSS), accounts for $\sim 85 \%$ of sporadic CRCs, while the microsatellite instability-high (MSI-H) pathway accounts for $\sim 15 \%$ of sporadic CRCs and is the alternate pathway of colorectal carcinogenesis (4-6). In the MSS pathway, tumors with chromosomal instability show frequent aneuploidy, as well as an allelic imbalance resulting in the inactivation of the tumor suppressor genes and mutations in the oncogenes (7-9). Microsatellite instability (MSI) is defined as a novel-length allele within a tumor, which is absent in the normal tissue and is considered to be a biomarker of DNA mismatch repair (MMR) deficiency. A defective DNA MMR system leads to an accumulation of somatic alterations in the coding and non-coding regions with nucleotide repeat sequences (10). In hereditary non-polyposis colon cancer (HNPCC), MSI has been attributed to mutations in the loci coding for hMLH1 or hMSH2, the two of which are important regulators of the MMR system $(11,12)$. The defect of the MMR system in sporadic CRC is generally caused by promoter hypermethylation of the $h M L H 1$ gene, which in turn results in transcriptional silencing, thus leading to MSI $(13,14)$. MSI has been studied as a hallmark of hMLH1 deficiency in sporadic CRCs. The MSI status in CRC specimens has also been investigated in relation to the patient prognosis or the 
sensitivity to 5-FU therapy. It has been widely reported that CRC patients with MSI-H confer more favorable outcomes and a higher sensitivity to chemotherapy by $5-\mathrm{FU}$, in comparison to those with MSS $(15,16)$. Moreover, MMRdeficient CRC is reported to have a better prognosis than MMR-competent cancer (17). However, several studies have demonstrated the controversial relationship between MMR expression and patient prognosis $(18,19)$. Therefore, whether or not MMR expression is a critical determinant for the prognosis of patients with CRC still remains to be elucidated.

In the present study, we quantitatively analyzed the hMLH1 mRNA expression in the resected cancer tissues from CRC patients, who received 5-FU-based adjuvant chemotherapy. Furthermore, we investigated the methylation status of the hMLHI gene in DNA from the CRC tissues. Then, the relationship between the $h M L H 1$ mRNA level or the methylation status and tumor recurrence was analyzed. We herein report that, among the patients receiving 5-FU-based adjuvant chemotherapy, the patients with low $h M L H 1$ mRNA expression levels in the colorectal cancer cells had a significantly longer disease-free survival than the patients with high $h M L H 1$ levels.

\section{Materials and methods}

Patients and tissue samples. We studied the colorectal cancer tissue and adjacent normal mucosa specimens from 94 patients who underwent surgical resections at the Department of Surgery, Saga University Hospital from December 1999 to August 2005. Informed consent for the use of the tissues was obtained from each of the patients. They consisted of 60 males and 34 females and the mean age was 68.2 years (ranging from 40 to 87 years). A total of 94 patients underwent a surgical resection with curative intent. A concomitant hepatic resection was performed with eight of the resections. Among the 94 patients, 35 patients with Dukes' stage C or D received 5-FU-based adjuvant chemotherapy after the surgical resection. The remaining 59 patients with Dukes' stage A or B did not receive such chemotherapy. The treatment consisted of intravenous fluorouracil or oral fluoropyrimidine and leucovorin. The mean administration time was 9.2 months, and the mean follow-up time was 26.1 months. The tumors were large enough to provide adequate amounts of tissues for a genetic analysis without compromising the pathological diagnosis. The tissue specimens from the non-necrotic areas of the tumor and from the adjacent normal mucosa were placed on ice immediately upon removal from the patient and then frozen at $-80^{\circ} \mathrm{C}$ until the DNA and RNA could be extracted from them. Each of the 94 tissue specimens were histologically confirmed to be adenocarcinoma of the colon and rectum. The degree of lymphatic invasion and venous invasion were graded into four groups (20): none, which included no evidence of vessel permeation by the tumor cells; mild, which involved the possible or doubtful presence of vessel permeation; moderate, which contained the definite presence of permeation to a few vessels; and marked, which comprised of the definite presence of permeation to many vessels. 'None' was graded as lymphatic (ly) or venous (v) 'negative' and 'mild' to 'marked' were graded as ly or v 'positive'.
Microdissection and RNA extraction. Laser capture microdissection was used to isolate the cancer foci, since certain colorectal cancers are extensively contaminated with adjacent normal cells. Serial $10-\mu \mathrm{m}$ sections were cut from the frozen tissue specimens and mounted on slides. The slides were then stained with hematoxylin and eosin and a coverslip was placed on one slide from each tumor and normal mucosa. The slides with coverslips were used to localize the lesions of interest for microdissection on the other slides. Using the laser capture microdissection system (PixCell II e Microscope, Arcturus Engineering, Mountain View, CA, USA) and the guidance of a pathologist, 2,000-3,000 cells were isolated from one or two sections of each tumor, then the RNA was extracted from the isolated cells with a PicoPure ${ }^{\text {TM }}$ RNA isolation kit (Arcturus).

Quantitative reverse transcription-polymerase chain reaction. The RNA samples were converted into cDNA by reverse transcriptase using a cDNA synthesis kit 1st strand with AMV reverse transcriptase (Takara Biochemicals, Shiga, Japan) according to the manufacturer's instructions. In order to quantitatively estimate the expression level of the hMLH1 mRNA, polymerase chain reaction amplification was performed on a Light-Cycler ${ }^{\mathrm{TM}}$ instrument system (Roche, Mannheim, Germany) using the Light-Cycler-FastStart DNA Master $^{\mathrm{TM}}$ SYBR-Green I kit (Roche) according to the manufacturer's instructions. After a denaturing step at $95^{\circ} \mathrm{C}$ for $3 \mathrm{~min}$, PCR amplification was performed with 50 cycles of $15 \mathrm{sec}$ denaturing at $95^{\circ} \mathrm{C}, 5 \mathrm{sec}$ annealing at $60^{\circ} \mathrm{C}$ and a $10 \mathrm{sec}$ extension at $72^{\circ} \mathrm{C}$. Melting curves were obtained according to the protocol under the following conditions: $0 \mathrm{sec}$ denaturation period at $95^{\circ} \mathrm{C}$, starting temperature of $65^{\circ} \mathrm{C}$, ending temperature of $95^{\circ} \mathrm{C}$ and a rate of temperature increase of $0.1^{\circ} \mathrm{C} / \mathrm{sec}$. The sequences of the PCR primer pair were $5^{\prime}$-AAC TGCAGTCCTTTGAGGAT-3' and 5'-CCATCAGCTGTT TTCGTTGT-3' for hMLH1 and 5'-TTAAGGAGAAGCTGT GCTACG-3' and 5'-GTTGAAGGTAGTTTCGTGGAT-3' for $B$-actin (as an internal control). These experiments were carried out in triplicate and the mean value was then calculated. The quantitative value was normalized by the $\beta$-actin expression. The mean relative value of the 94 patients was estimated as a cut-off value, which was obtained by dividing the 94 tissue specimens into either high or low $h M L H 1$ expression groups.

Methylation analysis. Genomic DNA from the tissue samples was isolated using an EZ1 DNA tissue kit (Qiagen, Hilden, Germany). The methylation status of the $h M L H 1$ promoter was determined by methylation-specific PCR (MSP), as previously described (21). Briefly, $1 \mu \mathrm{g}$ of DNA was subjected to a urea/bisulfite treatment according to the method of Paulin et al (22), in which the unmethylated cytosines are converted to uracils. Then, $1 \mu 1$ of modified DNA was subjected to PCR using Hot Start Ex Taq DNA polymerase (Takara Biochemicals) with the primers designed to recognize the bisulfite-induced uracil from the unmethylated cytosines, as previously described (21). The primer sequences were 5'-ACGTAGACGTTTTATTAGGGTCGC-3' and 5'-CCTC ATCGTAACTACCCGCG-3' for the methylated hMLH1 and 5'-TTTTGATGTAGATGTTTTATTAGGGTTGT-3' and 


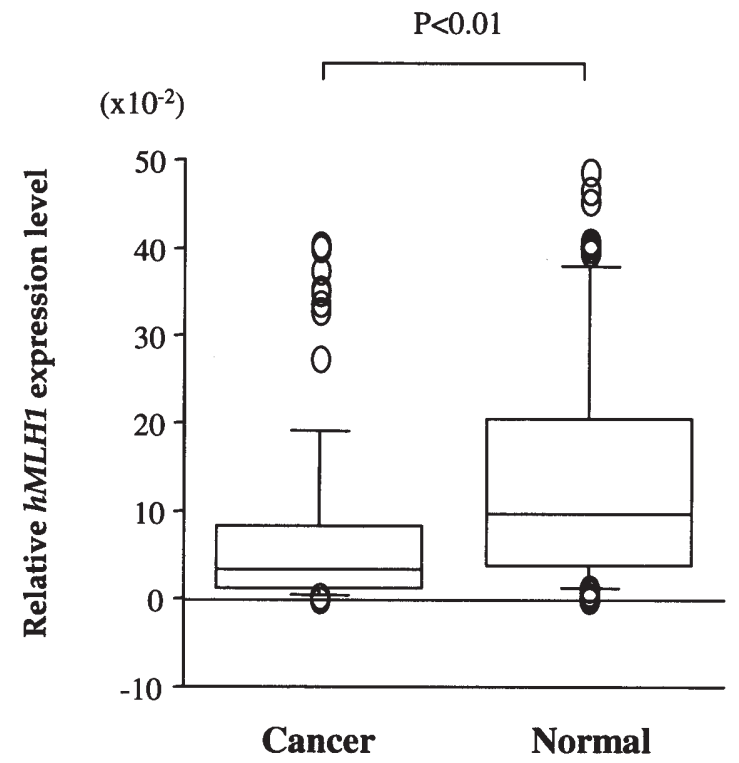

Figure 1. Relative $h M L H 1$ mRNA expression levels estimated in cancer cells and adjacent normal mucosa.

5'-ACCACCTCATCATAACTACCCACA-3' for the unmethylated hMLH1. The conditions for PCR amplification were as follows: $96^{\circ} \mathrm{C}$ for $3 \mathrm{~min} ; 35$ cycles at $96^{\circ} \mathrm{C}$ for $30 \mathrm{sec}$, $60^{\circ} \mathrm{C}$ for $30 \mathrm{sec}$ and $72^{\circ} \mathrm{C}$ for $30 \mathrm{sec}$; and finally, 4 min at $72^{\circ} \mathrm{C}$. The PCR products were separated on $1.5 \%$ agarose gels. In vitro methylated DNA (Intergen, Purchase, NY, USA) was used as a positive control for methylation and DNA from the normal lymphocytes was used as a negative control for methylation. Water without template DNA was used as a negative control. Each MSP was repeated at least twice.

Statistical analysis. A statistical analysis was performed using the StatView ${ }^{\mathrm{TM}}$ version 5.0 software program (SAS Institute Inc., Cary, NC, USA). The differences in frequencies were analyzed with the Fisher's exact test or the $\chi^{2}$ test and the differences in means were evaluated by the Mann-Whitney $\mathrm{U}$ test. The survival rates were calculated by the Kaplan-Meier method and the differences between the individual rates were evaluated by the log-rank test. In order to elucidate the risk factor for tumor recurrence, a multivariate analysis was performed using the logistic regression model. Tumor recurrence, which occurred within 20 months after surgery, was considered as 'recurrence present'. A P-value $<0.05$ was considered to be statistically significant.

\section{Results}

The hMLH1 expression in microdissected cancer cells and normal mucosa. For each of the 94 patients, the mean relative hMLH1 mRNA expression level was $7.3 \times 10^{-2}$ in the cancer cells and $14.1 \times 10^{-2}$ in the adjacent normal mucosa. As shown in Fig. 1, the relative $h M L H 1$ mRNA expression levels were significantly lower in the cancer cells than in the normal mucosa $(\mathrm{p}<0.01)$.

Relationship between the relative hMLH1 expression level and the methylation status of the hMLH1 promoter in colorectal cancer tissue. For each of the 94 patients, the mean relative
Table I. Relationship between $h M L H I$ expression and patient characteristics.

\begin{tabular}{|c|c|c|c|}
\hline \multirow[b]{2}{*}{ Factors } & \multicolumn{2}{|c|}{$h M L H 1$} & \multirow[b]{2}{*}{ P-value } \\
\hline & $\underset{(n=25)}{\text { High }}$ & $\begin{array}{c}\text { Low } \\
(n=69)\end{array}$ & \\
\hline Age (years) & & & 0.526 \\
\hline$\leq 60$ & 7 & 15 & \\
\hline$>60$ & 18 & 54 & \\
\hline Gender & & & 0.613 \\
\hline Male & 17 & 43 & \\
\hline Female & 8 & 26 & \\
\hline Location & & & 0.609 \\
\hline Right $(\mathrm{C}, \mathrm{A}, \mathrm{T})$ & 9 & 21 & \\
\hline Left (D, S, RS, R) & 16 & 48 & \\
\hline Primary tumor & & & 0.644 \\
\hline $\mathrm{T} 1-\mathrm{T} 2$ & 5 & 11 & \\
\hline T3-T4 & 20 & 58 & \\
\hline Lymph node metastasis & & & 0.838 \\
\hline Positive & 14 & 37 & \\
\hline Negative & 11 & 32 & \\
\hline Distant metastasis & & & 0.757 \\
\hline Positive & 2 & 9 & \\
\hline Negative & 23 & 60 & \\
\hline Histological type & & & 0.599 \\
\hline Tubl/tub2 & 24 & 62 & \\
\hline Others & 1 & 7 & \\
\hline Dukes' stage & & & 0.964 \\
\hline A-B & 11 & 30 & \\
\hline C-D & 14 & 39 & \\
\hline
\end{tabular}

hMLH1 mRNA expression level in the cancer cells was $3.5 \times 10^{-2}$ and $8.2 \times 10^{-2}$ in the colorectal cancer tissue with methylated or unmethylated $h M L H 1$ promoters, respectively. The relative $h M L H 1$ mRNA expression levels in the cancer cells were significantly lower in the colorectal cancer tissue with methylated versus unmethylated $h M L H 1$ promoters $(\mathrm{p}<0.01)$ (Fig. 2).

Correlations between hMLH1 expression and the clinicopathological features in patients with colorectal cancer. The comparative studies, which examined the $h M L H 1$ mRNA expression in cancer cells and the clinicopathological features in the 94 patients are summarized in Table I. No correlation was found in the hMLHI mRNA expression level with various factors such as age, gender, location, primary tumor, lymph node metastasis, distant metastasis, histological type and Dukes' stages. We then examined the relationship between the $h M L H 1$ mRNA expression level and the clinicopathological features in 35 patients with Dukes' stage C or D, who received 5-FU-based adjuvant chemotherapy after a surgical resection (Table II). Among these patients, the hMLH1 expression level was significantly associated with $\mathrm{v}$ (venous invasion) ( $\mathrm{p}=0.012)$ and tumor recurrence (within 20 months after surgery) $(\mathrm{p}<0.01)$. No correlation was found in the $h M L H 1$ expression level with other factors such as age, 


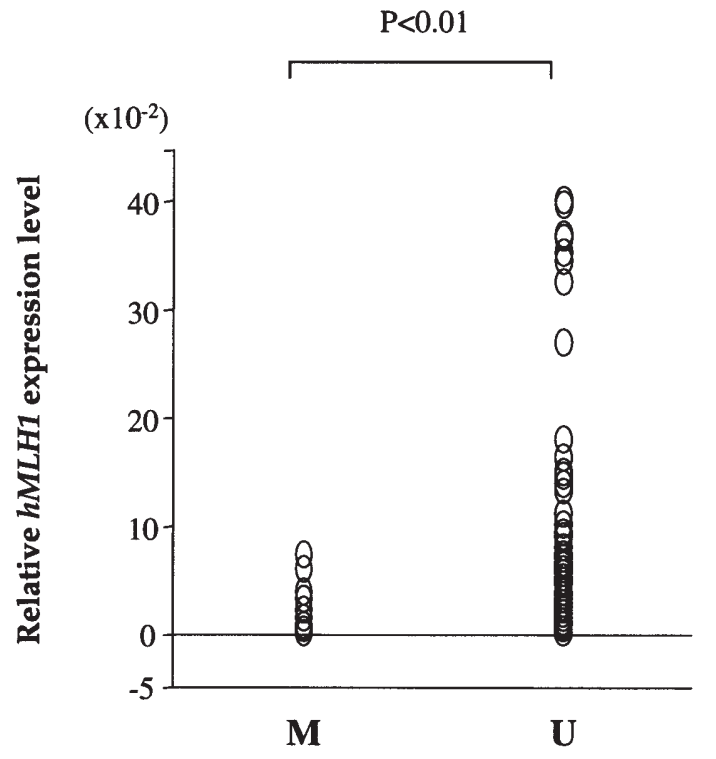

Figure 2. Relationship between the relative $h M L H 1$ mRNA expression levels and the methylation status of the $h M L H 1$ promoter in colorectal cancer tissue. M, Methylated; U, unmethylated.

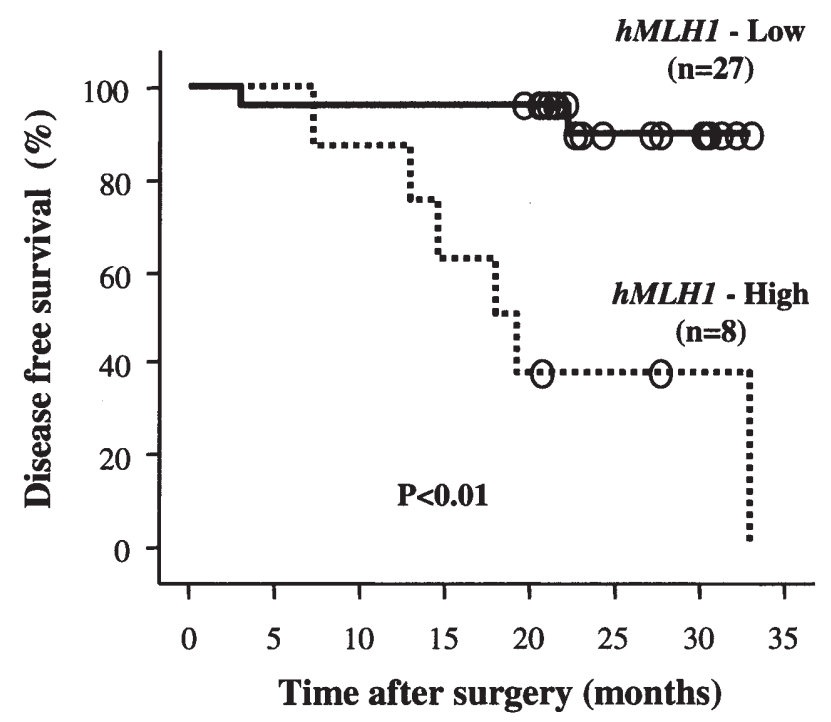

Figure 3. Disease-free survival rate by the $h M L H 1$ mRNA expression levels in cancer cells.

gender, location, histological type, ly (lymphatic vessel invasion), primary tumor, lymph node metastasis, distant metastasis, cancers of multiple organs and mean administration time.

Associations between hMLH1 expression or methylation status of the hMLH1 promoter and the survival of colorectal cancer patients receiving adjuvant chemotherapy after a surgical resection. Among the 35 colorectal cancer patients receiving 5-FU-based adjuvant chemotherapy after a surgical resection, there was no significant correlation between either the $h M L H 1$ mRNA expression in the cancer cells or the methylation status of the $h M L H 1$ promoter in the colorectal cancer tissue and the overall survival rate (data not shown). However, the disease-free survival rate in these 35 patients
Table II. Relationship between $h M L H I$ expression and clinicopathological features in patients receiving adjuvant chemotherapy.

\begin{tabular}{|c|c|c|c|}
\hline \multirow[b]{2}{*}{ Factors } & \multicolumn{2}{|c|}{$h M L H 1$} & \multirow[b]{2}{*}{ P-value } \\
\hline & $\begin{array}{l}\text { High } \\
(n=8)\end{array}$ & $\begin{array}{c}\text { Low } \\
(n=27)\end{array}$ & \\
\hline Age (years) & & & 0.133 \\
\hline$\leq 60$ & 5 & 7 & \\
\hline$>60$ & 3 & 20 & \\
\hline Gender & & & 0.109 \\
\hline Male & 8 & 17 & \\
\hline Female & 0 & 10 & \\
\hline Location & & & 0.742 \\
\hline Right $(\mathrm{C}, \mathrm{A}, \mathrm{T})$ & 7 & 20 & \\
\hline Left (D, S, RS, R) & 1 & 7 & \\
\hline Histological type & & & 0.774 \\
\hline Tubl/tub2 & 8 & 24 & \\
\hline Others & 0 & 3 & \\
\hline Lymphatic vessel invasion (ly) & & & 0.344 \\
\hline Positive & 8 & 21 & \\
\hline Negative & 0 & 6 & \\
\hline Venous invasion (v) & & & 0.012 \\
\hline Positive & 7 & 8 & \\
\hline Negative & 1 & 19 & \\
\hline Primary tumor & & & 0.774 \\
\hline $\mathrm{T} 1-\mathrm{T} 2$ & 0 & 3 & \\
\hline T3-T4 & 8 & 24 & \\
\hline Lymph node metastasis & & & 0.588 \\
\hline Positive & 8 & 23 & \\
\hline Negative & 0 & 4 & \\
\hline Distant metastasis & & & 0.764 \\
\hline Positive & 0 & 4 & \\
\hline Negative & 8 & 23 & \\
\hline Cancers of multiple organs & & & 0.344 \\
\hline Present & 0 & 6 & \\
\hline Absent & 8 & 21 & \\
\hline Recurrence & & & $<0.01$ \\
\hline Present & 5 & 1 & \\
\hline Absent & 3 & 26 & \\
\hline $\begin{array}{l}\text { Mean administration time } \\
\text { (months) }\end{array}$ & 10.4 & 8.9 & $>0.999$ \\
\hline
\end{tabular}

demonstrated that the high $h M L H 1$ mRNA expression in the cancer cells was significantly worse than that of the patients with the low $h M L H 1$ mRNA expression (p<0.01) (Fig. 3). In addition, a multivariate analysis revealed the $h M L H 1$ mRNA expression to be a significant independent risk factor for tumor recurrence (within 20 months after surgery) in the colorectal cancer patients receiving 5-FU-based adjuvant chemotherapy after a surgical resection $(\mathrm{p}=0.015)$. The relationship between the methylation status of the $h M L H 1$ promoter in the colorectal cancer tissue and the disease-free survival rate did not demonstrate any statistical significance (Fig. 4). 
Table III. Logistic regression analysis for risk factor contributing tumor recurrence in patients receiving adjuvant chemotherapy.

\begin{tabular}{|c|c|c|c|c|}
\hline \multirow[b]{2}{*}{ Variables } & \multirow{2}{*}{$\begin{array}{c}\text { Univariate } \\
\text { P-value }\end{array}$} & \multicolumn{3}{|c|}{ Multivariate } \\
\hline & & Risk ratio & $95 \% \mathrm{CI}$ & P-value \\
\hline hMLHI & & & & \\
\hline $\begin{array}{l}\text { High } \\
\text { Low }\end{array}$ & 0.008 & 3.397 & $1.928-462.8$ & 0.015 \\
\hline $\begin{array}{c}\text { Venous in } \\
\text { Positive } \\
\text { Negative }\end{array}$ & 0.027 & 0.753 & 0.115-39.09 & 0.612 \\
\hline
\end{tabular}

CI, Confidence interval.

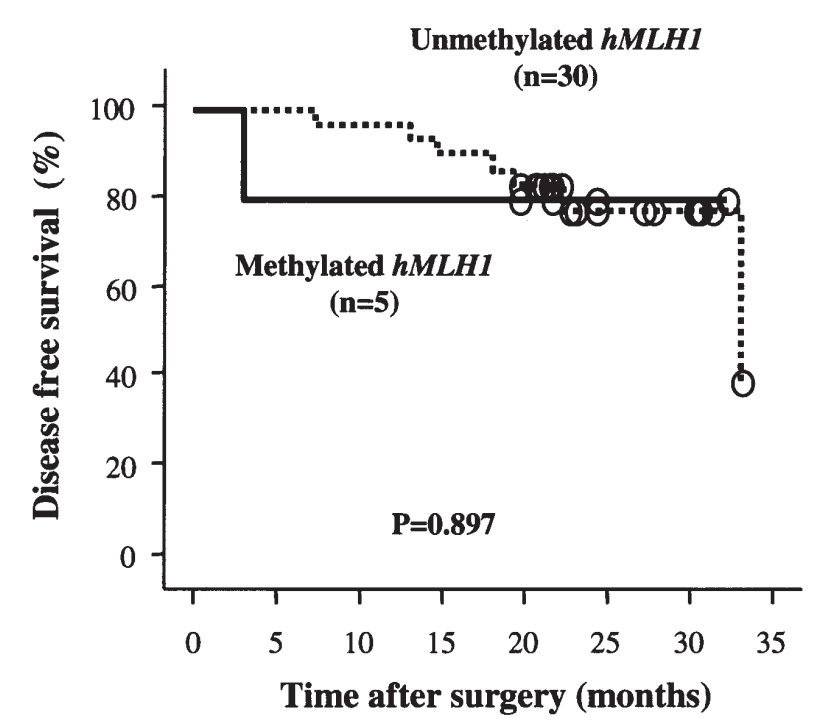

Figure 4. Disease-free survival rate by the methylation status of the $h M L H 1$ promoter in colorectal cancer tissue.

\section{Discussion}

Surgical resection has been mainly performed on patients with CRC and has contributed to constantly decreasing death rates. In addition, 5-FU-based adjuvant chemotherapy is the standard treatment after surgery for advanced-stage CRC, such as International Union Against Cancer (UICC) stage III colon cancer and UICC stage II and III rectal cancer. Although the recurrence rate is reduced using this adjuvant treatment, the survival advantage accounts for only 10-20\% (23). It would therefore be desirable to identify those patients who are likely to benefit from adjuvant 5-FU treatment before the initiation of such therapy. Studies have revealed that a low TS, low DPD and high OPRT expression, which are all 5-FU-related metabolic enzymes, predict an increased effectiveness of 5-FU therapy (24-26). However, the relationship between the MSI-H and the sensitivity to 5-FU has not yet been fully demonstrated. In our study, we investigated whether the expression level of hMLH1 mRNA or the methylation status of this gene is associated with the prognosis of CRC patients treated with adjuvant 5-FU after surgery.

In order to retrospectively examine the prognostic relevance of $h M L H 1$ mRNA expression to the survival of
CRC patients, we established a method which enabled us to quantify the gene expression from fresh-frozen tissues using laser capture microdissection (LCM). Of the 94 patients, the relative $h M L H 1$ mRNA expression levels were significantly lower in the cancer cells than in the normal mucosa $(\mathrm{p}<0.01)$ and we found a significant correlation between the quantity of hMLH1 mRNA and the methylation status in the 94 colorectal cancer tissues $(\mathrm{P}<0.01)$ (Fig. 2). The methylated hMLH1 promoter in the CRC tissues was found in 14 of the 94 patients (14.9\%). These results indicate that a low $h M L H 1$ mRNA expression may be caused by promoter hypermethylation of the $h M L H 1$ gene. Previous studies have shown that an MSI-H incidence of $\sim 15-20 \%$, which was similar to the population of hMLH1 methylation in this study, has been observed in sporadic CRCs (6). Taken together, the hMLH1 promoter methylation results in the suppressed mRNA expression of this gene. These sequential events may cause MSI-H in sporadic CRCs.

In a multivariate analysis of CRC patients who received adjuvant 5-FU therapy, we demonstrated for the first time that the $h M L H 1$ mRNA expression level in cancer cells is an independent factor determining tumor recurrence (Table III). Regarding the disease-free survival rate, a low $h M L H 1$ level was associated with a longer survival in the $35 \mathrm{CRC}$ patients who received adjuvant therapy. Hemminki et al (5) studied a group of 95 stage III CRC patients prospectively. In this literature, the 3-year disease-free survival rate was significantly higher for the MSI-H patients $(n=11)$, where it amounted to $90 \%$, than for the MSS patients $(n=84)$. Elsaleh et al retrospectively analyzed 656 consecutive patients with stage III CRC with a median follow-up of 54 months. The authors found that the patients with MSI-H tumors had a $90 \%$ chance of survival at the end of the study when they received 5-FU-based chemotherapy, in comparison to a $35 \%$ survival when no chemotherapy was administered (18). In palliative first-line treatment, it has been reported that MSI-H CRCs may have a better response to 5-FU therapy and survival than MSS CRCs (27). These reports support our belief that the low $h M L H 1$ expression in the colorectal cancer cells resulted in a better survival and lower recurrence rate after 5-FU-based chemotherapy.

In contrast, several clinical studies have not found any differences in the chemotherapy response between patients with MMR-deficient and competent tumors (17). Other 
studies have found a better prognosis in patients with MSS or low-frequency microsatellite instability (MSI-L) who received adjuvant 5-FU-based chemotherapy $(15,16)$. Therefore, the clinical evidence on survival or sensitivity to 5-FU therapy in MSI-H CRCs is conflicting and undetermined. Taken together, the assessment of the MMR expression level, which directly affects the MSI status, is suggested to solve the controversy described above. In our study, we quantitatively analyzed the $h M L H 1$ mRNA from the cancer cells isolated by LCM and showed a significant association between the hMLH1 mRNA level and patient prognosis. This finding directly indicated that the assessment of the $h M L H 1$ expression level in primary CRCs may predict tumor recurrence after 5-FU-based adjuvant chemotherapy. However, we observed no significant relationship between the methylation status of the $h M L H 1$ promoter and the survival rate in the 35 colorectal cancer tissues with Dukes' stage $\mathrm{C}$ or D (Fig. 4). In the remaining 59 patients with Dukes' stage A or B, the low $h M L H 1$ expression showed a statistically significant correlation with the $h M L H 1$ methylation $(\mathrm{p}=0.029)$ (data not shown). These results suggest that another mechanism, such as genetic mutation or deletion of the $h M L H 1$ gene, may occur in advanced CRC with Dukes' stage C or D.

To our knowledge, this study showed the first evidence regarding the relationship between the recurrence-free survival rate after 5-FU treatment and the expression level of the $h M L H 1$ gene. In order to clarify whether or not low $h M L H 1$ expression contributes to the sensitivity to 5-FU, a comparative study between chemotherapy and surgery groups alone should be performed in CRC patients with Dukes' stage C or D. At present, only nine of the patients underwent surgery alone and such a comparison could not reach statistical relevance (data not shown). If the larger number of patients who did not receive adjuvant therapy would be taken into account, our study would emphasize the implication of the $h M L H 1$ expression in the sensitivity to 5-FU treatment. In the future, more randomized control trials will be required in order to assess the significance of $h M L H 1$ mRNA expression in the effectiveness of 5-FU-based treatment.

In conclusion, our study indicates that the quantitation of hMLH1 mRNA expression level in colorectal cancer cells may be useful in predicting the prognosis of CRC patients receiving 5-FU-based adjuvant chemotherapy after surgery. It may subsequently lead to an individualized and optimized cancer treatment based on the molecular characteristics of the types of tumors involved in CRCs.

\section{References}

1. Greenlee RT, Murray T, Bolden S and Wingo PA: Cancer statistics 2000. CA Cancer J Clin 50: 7-33, 2000.

2. Midgley R and Kerr D: Colorectal cancer. Lancet 353: 391-399, 1999.

3. Link KH, Staib L, Kreuser ED and Beger HG: Adjuvant treatment of colon and rectal cancer: impact of chemotherapy, radiatiotherapy, and immunotherapy on routine postsurgical patient management. Rec Results Cancer Res 142: 311-352, 1996.

4. Gryfe R, Kim H, Hsieh ET, et al: Tumor microsatellite instability and clinical outcome in young patients with colorectal cancer. $\mathrm{N}$ Engl J Med 342: 69-77, 2000.
5. Hemminki A, Mecklin JP, Jarvinen H, et al: Microsatellite instability is a favorable prognostic indicator in patients with colorectal cancer receiving chemotherapy. Gastroenterology 119: 921-928, 2000.

6. Thibodeau SN, Bren G and Schaid D: Microsatellite instability in cancer of the proximal colon. Science 260: 816-819, 1993.

7. Lengauer C, Kinzler KW and Vogelstein B: Genetic instability in colorectal cancers. Nature 386: 623-627, 1997.

8. Cahill DP, Lengauer C, Yu J, et al: Mutations of mitotic checkpoint genes in human cancers. Nature 392: 300-303, 1998.

9. Kinzler KW and Vogelstein B: Lessons from hereditary colorectal cancer. Cell 87: 159-170, 1996.

10. Perucho M: Microsatellite instability: the mutator that mutates the other mutator. Nat Med 2: 630-631, 1996.

11. Lindblom A, Tannergard P, Werelius B and Nordenskjold M: Genetic mapping of a second locus predisposing to hereditary non-polyposis colon cancer. Nat Genet 5: 279-282, 1993.

12. Bronner CE, Baker SM, Morrison PT, et al: Mutation in the DNA mismatch repair gene homologue hMLH1 is associated with hereditary non-polyposis colon cancer. Nature 368: 258-261, 1994.

13. Cunningham JM, Christensen ER, Tester DJ, et al: Hypermethylation of the hMLH1 promoter in colon cancer with microsatellite instability. Cancer Res 58: 3455-3460, 1998.

14. Herman JG, Umar A, Polyak K, et al: Incidence and functional consequences of hMLH 1 promoter hypermethylation in colorectal carcinoma. Proc Natl Acad Sci USA 95: 6870-6875, 1998.

15. Carethers JM, Smith EJ, Behling CA, et al: Use of 5-fluorouracil and survival in patients with microsatellite-unstable colorectal cancer. Gastroenterology 126: 394-401, 2004.

16. Benatti P, Gafa R, Barana D, et al: Microsatellite instability and colorectal cancer prognosis. Clin Cancer Res 11: 8332-8340, 2005.

17. Jover R, Zapater P, Castells A, et al: Mismatch repair status in the prediction of benefit from adjuvant fluorouracil chemotherapy in colorectal cancer. Gut 55: 848-855, 2006.

18. Elsaleh H, Joseph D, Grieu F, et al: Association of tumour site and sex with survival benefit from adjuvant chemotherapy in colorectal cancer. Lancet 355: 1745-1750, 2000.

19. Watanabe T, Wu TT, Catalano PJ, et al: Molecular predictors of survival after adjuvant chemotherapy for colon cancer. N Engl J Med 344: 1196-1206, 2001

20. Jinnai D: General rules for clinical and pathological studies on cancer of the colon, rectum, and anus. Part I. Clinical classification. Japanese Research Society for Cancer of the Colon and Rectum. Jpn J Surg 13: 557-573, 1983.

21. Koga Y, Kitajima Y, Miyoshi A, et al: Tumor progression through epigenetic gene silencing of $\mathrm{O}^{6}$-Methylguanine-DNA methyltransferase in human biliary tract cancers. Ann Surg Oncol 12: 1-10, 2005.

22. Paulin R, Grigg GW, Davey MW and Piper AA: Urea improves efficiency of bisulfite-mediated sequencing of 5'-methylcytosine in genomic DNA. Nucleic Acids Res 26: 5009-5010, 1998.

23. Cascinu S, Georgoulias V, Kerr D, et al: Colorectal cancer in the adjuvant setting: perspectives on treatment and the role of prognostic factors. Ann Oncol 14: 25-29, 2003.

24. Salonga D, Danenberg DK, Johnson M, et al: Colorectal tumors responding to 5-fluorouracil have low gene expression levels of dihydropyrimidine dehydrogenase, thymidylate synthase, and thymidine phosphorylase. Clin Cancer Res 6: 1322-1327, 2000 .

25. Etienne MC, Cheradame S, Fischel JL, et al: Response to fluorouracil therapy in cancer patients: the role of tumoral dihydropyrimidine dehydrogenase activity. J Clin Oncol 13: 1663-1670, 1995.

26. Ochiai T, Nishimura K, Noguchi H, et al: Prognostic impact of orotate phosphoribosyl transferase among 5-fluorouracil metabolic enzymes in respectable colorectal cancers treated by oral 5-fluorouracil-based adjuvant chemotherapy. Int J Cancer 118: 3084-3088, 2006.

27. Brueckl WM, Moesch C, Brabletz T, et al: Relationship between microsatellite instability, response and survival in palliative patients with colorectal cancer undergoing first-line chemotherapy. Anticancer Res 23: 1773-1778, 2003. 